\title{
A study to determine the dimensions of job satisfaction, job turnover tendency, individual personalities and psychological well-being in Tehran City Hall
}

\author{
Seyed Morteza Gholami AliAbadi ${ }^{a^{*}}$, Seyed Mohsen Seyed AliAkbar ${ }^{\mathrm{b}}$ and Kiamars Fathi
}

${ }^{a}$ Master student, Department of Industrial engineering, Islamic Azad University, South Tehran Branch, Tehran, Iran

${ }^{b}$ Department of Industrial Engineering, Islamic Azad University, South Tehran Branch, Tehran, Iran

${ }^{c}$ Department of Management, Islamic Azad University, South Tehran Branch, Tehran, Iran

\section{CHRON I C LE ABSTRACT}

\section{Article history:}

Received December 2, 2013

Accepted 8 May 2014

Available online

May 122014

Keywords:

Factor Analysis

Job Satisfaction

Turnover

Well-Being

Personality trait

Locking-in

\begin{abstract}
Among various indices of job attitudes, job satisfaction has gained especial attention by researchers and employers. Its measurement dates back to older times and the investigation of the influential factors on it are newer. Furthermore, because of its influences on organizations and people, job satisfaction has gained an increasing importance. Among various influential factors on job satisfaction and job turn over, the effect of individual personalities and psychological Well-Being is undeniable. In this article, we identify and categorize the significant factors in the four elements of job turnover, job satisfaction, individual traits and psychological Well-Being. We investigate nine factors of job satisfaction with 36 questions, two factors of the field of job turnover with seven questions, individual personalities with forty four questions and psychological Well-Being with eighteen questions and categorize them after doing a factor analysis. In this categorization, the dimensions of job satisfaction are reduced to seven dimensions. Job turnover is provided into two new dimensions. Individual personalities are categorized in eight main dimensions and the dimensions of psychological Well-Being are reduced to four dimensions. The data of this research has been gathered from 199 employees of Tehran city hall.
\end{abstract}

\section{Introduction}

The number of employees who quit their jobs is normally considered as an indicative index of the amount of job dependence by researchers and managers. Measuring this index can lead any firm to adopt proper and preventive policies, since losing human capitals may cost, significantly. According to Cascio (1986), these expenses can be divided into the undermentioned three general categories including quitting costs, substitution costs and training costs.

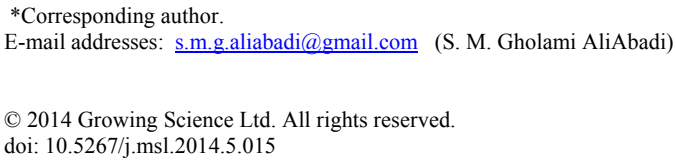


There are various individual, organizational and social factors influencing job quitting and the adoption of a suitable policy depends on the identification of job quitting reasons. Being separated from a particular firm does not occur, spontaneously and different factors are normally involved in the formation of the idea of being separated from a firm and the factors include general and economic factors, job related factors as well as individual factors (Muchinsky \& Morrow, 1980). Wright and Bonett (2007) investigated two main categories of these factors based on a regression model and studied the impact of the personalities of psychological Well-Being and job satisfaction on job turnover. The job turnover was incorporated in the model such that the state of the presence of the samples being studied in the current job after two years. They reported that when a person's level of psychological Well-Being is low, job satisfaction leads to job quitting, more strongly. Hom and Griffeth (1995) performed an investigation on job satisfaction as a predictor of job turnover where the index of job satisfaction seemed to act better in the explanation of the calculated variance compared with the dimensions of job satisfaction like colleagues, work, communications, etc.

\subsection{Job satisfaction}

Job satisfaction is defined as a collection of individual interactions, job factors, organizational variables and environmental elements. Experts have provided various definitions of the concept of job satisfaction. According to Arnold and Feldman (1986), job satisfaction is defined as the most important attitude of job and claimed that job satisfaction depends on employees' attitude towards the job and organization. When an employee has a high job satisfaction, it means that they generally like their job, consider that worthy and have a positive attitude towards that. Generally, this judgment like others does not depend on one index. Spector provided nine indices for job satisfaction mentioned along with their reliability in what follows (JSS). According to the George and Mallery (2003), the reliabilities of the indices have fallen in good ranges.

\section{Table1}

Dimensions and their Reliabilities in JSS

\begin{tabular}{ccccc}
\hline Salary & Supervision & Reward & Coworkers & Communications \\
\hline 0.75 & 0.83 & 0.73 & 0.6 & 0.971 \\
\hline Promotion & Benefits & Conditions & Work itself & General \\
\hline 0.73 & 0.73 & 0.62 & 0.78 & 0.91 \\
\hline
\end{tabular}

Smith et al. (1969) designed five dimensions for the measurement of job satisfaction including salary, promotions, job nature, supervision, colleagues. Also various valid questionnaires associated with the measurement of job satisfaction have been prepared and applied repeatedly by researchers around the world. These factors in the design of these questionnaires have been categorized in different researches. AkbariTabar et al. (2013) measured job satisfaction of 415 physicians and nurses through this questionnaire and using factor analysis, they reported that some of the dimensions considered in the design of the questionnaire were not found significant. Exploratory factor analysis also identified the some extra dimensions including payment, promotion, supervision, colleagues, job nature and communications. Astrauskaite et al. (2011) considered 351 teachers as the sample and by performing the factor analysis, nine dimensions of the questionnaire were not verified and only three dimensions of promotion, the job itself and supervision were verified. Gholami Fesharaki (2012) measured the reliability of the nine dimensions of Spector questionnaire in army treatment cadre, which reached the acceptable value. The factor analysis of this questionnaire led to the discovery of seven factors including the intakes and rewards, supervision, job nature, communications, promotion, Processes and colleagues.

\subsection{Job turnover}

The amount of job turnover is one of the indicative indices of the amount of job dependence applied by researchers and managers. Measuring this index will lead a firm to the adoption of suitable and 
preventive policies since the loss of human capitals imposes enormous expenses on the organization, the costs can be divided to the following three general categories of separation costs, substitution costs, training costs (Cascio, 1986).

Since various individual, organizational and social factors may impact job quitting, the adoption of appropriate policies depends on the identification of the reasons of job quitting. In this area, one of the factors, which plays essential role in the whole process of turnover, is the presence of similar job opportunities in the substitute organizations (March \& Simon, 1958). This is natural that a person thinks seriously about job quitting and looks for a new job when he/she believes there is another organization that provides similar salary, bonus, etc. Otherwise, the tendency to quit one's job will not lead to their job quitting and looking for a new job. According to Lacity and Rudramuniyaiah (2008), job turnover is investigated based on two main factors. The first factor measures turnover tendencies and the second one measures the presence of the substitute organizations. This took place through asking the questions like: is there a job at least as good as your present job in other organizations? or Can you find your favorite job easily?

In the Michigan questionnaire of organizational evaluation designed for the evaluation of the organization members' perceptions, job turnover was questioned in three areas of tendency of external turnover, internal turnover and Locking-in through eight questions.

\subsection{Individual Personalities}

Khanka (2010) defined personality as a set of ways through which the person interacts with others and the environment. In other words, personality is an organized behavior of a person to react to a definite stimulus in a suitable way. This reaction is often in a form of a permanent response to an environmental stimulus. A person's personality is impacted by their individual life and the place in which they work. Regarding the presence of various definitions of personality, there are many theories. The model of big five considers five variables, extraversion, adaptation, responsibility, emotional stability and experience openness, by the main dimensions of personality and covers all the other variables. Based on this, different questionnaires are designed for the evaluation of the person's personality. As an example we can refer to the 44-item questionnaire of John and Sriovastave that evaluates these five dimensions in 44 questions.

In a research by Block (2001), five factors were reduced to two factors: The first factor was indicative of the process of socialization which included some traits in the areas of consciousness, reduction of aggression and limitations and the second factor included traits about personality growth, positive feeling, brave confrontation with life and imagination.

\subsection{Psychological Well-being}

According to Ryff (1989) and Ryff et al. (2013), the psychological Well-Being structure is something more than the mere absence of negative feelings or the presence of happiness. Psychological WellBeing is not just gaining pleasure but it is an effort for evolution which is a sign of realization of the person's real potentials. Psychological Well-Being includes six elements, which states weather a person is grappling with existential challenges or not. The dimensions of this element include:

1. Self- acceptance or positive attitude towards oneself,

2. positive relations with others or the ability of making close relations with others,

3. autonomy,

4. personal growth,

5. environmental mastery or the ability to participate or manage the functions in the world around,

6. purpose in life. 
McGregor and Little (1998) analyzed various set of mental health indices used by various researches and arrived at the two factors that were formed from these two indices. The first factor was reflecting happiness and the second one indicated the significance. Among the six dimensions of psychological Well-Being, self-acceptance and environmental mastery were associated with happiness and the other four dimensions were placed in the field of significance.

\section{The proposed study}

The purpose of this study is to identify and to categorize the factors of the four elements of job satisfaction, psychological Well-Being, job turnover and individual personalities among employees of Tehran city hall organization, this will provide useful information for the researchers to consider important factors in their researches through having the reliabilities of these questionnaires and the results of factor analysis.

\subsection{Methodology}

The questionnaires were distributed and gathered randomly among 300 employees of a district city hall In Tehran. Finally 199 questionnaires were completed and were useable. The value of Cronbach alpha was calculated for each questionnaire. Regarding the sensitivity of factor analysis to the absence of symmetry, some questions were omitted from the questionnaire. Every item was allocated five values from one to five representing very little, little, medium, much and very much, respectively.

Job satisfaction: The sample job satisfaction was measured through Spector job satisfaction questionnaire (JSS). One of the reasons to choose this questionnaire was that this questionnaire was basically designed for service organizations and adapts well to the purposes of this study. The questionnaire has 36 questions and investigates nine areas (each area four questions). The translated form of this questionnaire has already been used in various researches and its reliability was verified.

Job turnover: This was measured through Michigan organizational evaluation. The considered factors in this questionnaire were tendency to job turnover and locking- in to make sure about the accuracy of the questionnaire translation this questionnaire was translated by language experts and then was translated back to its original version by someone else.

Psychological well-being: The used questionnaire for measuring psychological well-being was Ryff's questionnaire (the 18-item version). To make sure about the accuracy of the questionnaire translation this version was translated by language experts and was then translated back to its original version by someone else.

Individual personalities: the sample individual personality was measured by a 44 item questionnaires, which evaluated five dimensions of personality.to make sure about the accuracy of the questionnaire translation this questionnaire was translated by language experts and then was translated back to its original version by someone else.

\section{Data Analysis and Results}

The questionnaires were distributed and were gathered after being answered. 300 questionnaires were distributed and 210 questionnaires were gathered. Among these, 199 questionnaires were appropriately answered, i.e. $66 \%$ of the distributed questionnaires were useable. $52.8 \%$ of the sample was women and $47.2 \%$ were men. $60.8 \%$ of the sample was married. Generally $94 \%$ of the sample members had academic education. $9 \%$ of the sample members had associate of art, $55.8 \%$ had BA or BS and $28.6 \%$ had higher education (the rest did not give their educational information). Regarding their organizational experience and their experience in their current job, the following state can be provided in Fig. 1 as follows, 


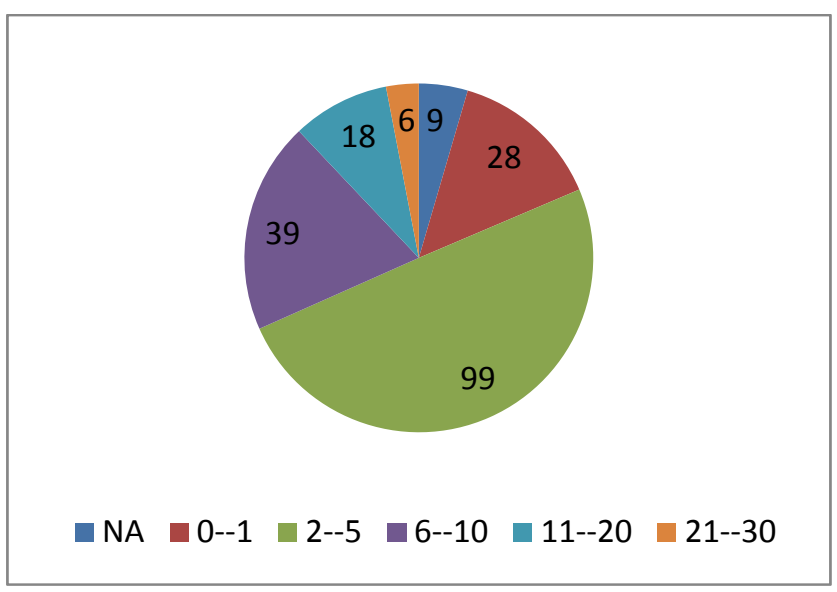

Job Experience in the current job

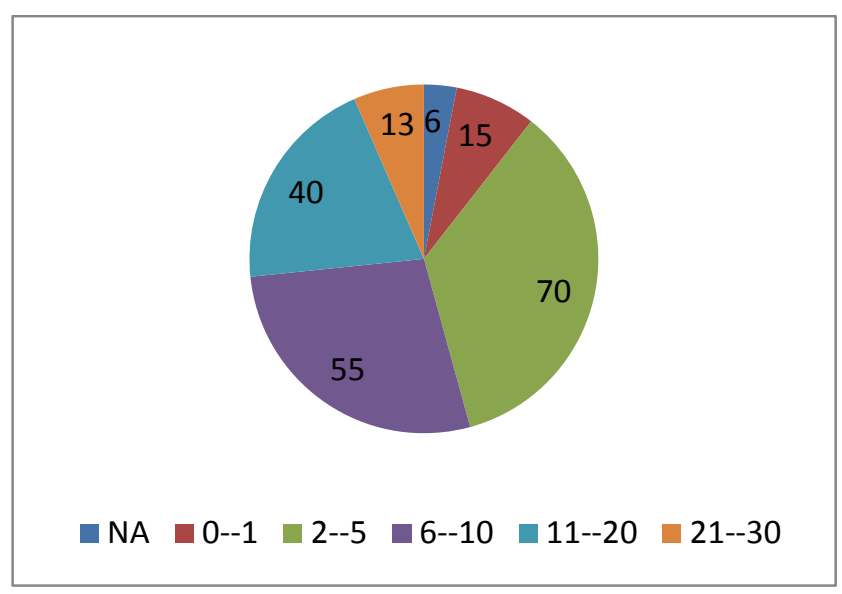

Job Experience within the firm

Fig. 1. Job experience in the current versus the firm

\subsection{Job satisfaction}

In the initial measurement, the value of Cronbach was calculated as 0.923 . After the required investigations including colinearity corrected item-total correlation, squared multiple correlation, Cronbach's alpha of item deleted and Skewness, some of the variables were deleted and finally alpha value was reduced to the favorable value of 0.891 and the factor analysis was done. The following data was gained, the determinant of correlation equaled 2.6E-005 and the percentage of the stated variance equaled $\% 61$. The resulted data of this analysis is provided in table 2 .

Table 2

Details of factor analysis of job satisfaction

\begin{tabular}{|c|c|c|c|c|c|c|c|}
\hline Factor & Name & Question & Factor & Eigenvalue & $\%$ of Variance & $\%$ Cumulative & Alpha \\
\hline \multirow{7}{*}{1} & \multirow{7}{*}{ Promotion } & 10 & .768 & \multirow{7}{*}{6.953} & \multirow{7}{*}{26.742} & \multirow{7}{*}{26.742} & \multirow{7}{*}{0.837} \\
\hline & & 11 & .766 & & & & \\
\hline & & 33 & 680 & & & & \\
\hline & & 2 & .624 & & & & \\
\hline & & 23 & .582 & & & & \\
\hline & & 13 & .529 & & & & \\
\hline & & 5 & .514 & & & & \\
\hline \multirow{3}{*}{2} & \multirow{3}{*}{ Income } & 19 & .771 & \multirow{3}{*}{2.553} & \multirow{3}{*}{9.821} & \multirow{3}{*}{36.653} & \multirow{3}{*}{0.70} \\
\hline & & 1 & .704 & & & & \\
\hline & & 4 & 619 & & & & \\
\hline \multirow{4}{*}{3} & \multirow{4}{*}{ Job itself } & 27 & .695 & \multirow{4}{*}{1.585} & \multirow{4}{*}{6.102} & \multirow{4}{*}{42.665} & \multirow{4}{*}{0.39} \\
\hline & & 24 & .668 & & & & \\
\hline & & 17 & .614 & & & & \\
\hline & & 8 & .612 & & & & \\
\hline \multirow{3}{*}{4} & \multirow{3}{*}{ Coworkers } & 25 & .798 & \multirow{3}{*}{1.389} & \multirow{3}{*}{5.342} & \multirow{3}{*}{48.006} & \multirow{3}{*}{0.68} \\
\hline & & 7 & .796 & & & & \\
\hline & & 34 & .611 & & & & \\
\hline \multirow{3}{*}{5} & \multirow{3}{*}{ Processes } & 28 & .705 & \multirow{3}{*}{1.286} & \multirow{3}{*}{4.945} & \multirow{3}{*}{48.006} & \multirow{3}{*}{0.619} \\
\hline & & 6 & .666 & & & & \\
\hline & & 36 & .428 & & & & \\
\hline \multirow{3}{*}{6} & \multirow{3}{*}{ Prohibiting } & 15 & .738 & & & & \\
\hline & & 16 & .547 & 1.091 & 4.195 & 57.146 & 0.396 \\
\hline & & 31 & .528 & & & & \\
\hline & & 9 & .656 & & & & \\
\hline 7 & Communication & 26 & .537 & 1.033 & 3.973 & 61.119 & 0.55 \\
\hline & & 18 & .337 & & & & \\
\hline
\end{tabular}




\subsection{Job Turnover}

The Cronbach's alpha of this questionnaire show the acceptable value of 0.681 . The determinant of correlation matrix equaled 0.181 and the stated variance equaled $70 \%$. The related data to this analysis is provided in table 4 .

Table 4

Details of factor analysis of job turnover

\begin{tabular}{|c|c|c|c|c|c|c|c|}
\hline Factor & Name & Question & $\begin{array}{l}\text { Factor } \\
\text { Weight }\end{array}$ & Eigenvalues & $\%$ of Variance & $\%$ Cumulative & Alpha \\
\hline \multirow{2}{*}{1} & \multirow{2}{*}{$\begin{array}{l}\text { Evaluating the } \\
\text { quitting }\end{array}$} & $\begin{array}{l}\text { Probability of Looking } \\
\text { for new job in the next year }\end{array}$ & 0.911 & \multirow{2}{*}{2.306} & \multirow{2}{*}{46.116} & \multirow{2}{*}{46.116} & \multirow{2}{*}{0.803} \\
\hline & & $\begin{array}{l}\text { Finding a new job with } \\
\text { the same pay \& benefits }\end{array}$ & 0.762 & & & & \\
\hline \multirow[b]{2}{*}{2} & \multirow[b]{2}{*}{$\begin{array}{l}\text { Proper } \\
\text { Alternatives }\end{array}$} & Staking in current job & 0.862 & \multirow[b]{2}{*}{1.212} & \multirow[b]{2}{*}{24.249} & \multirow[b]{2}{*}{70.365} & \multirow[b]{2}{*}{0.47} \\
\hline & & $\begin{array}{l}\text { dreading of quitting the job } \\
\text { without another one being lined } \\
\text { up }\end{array}$ & 0.734 & & & & \\
\hline
\end{tabular}

\subsection{Individual Traits}

The Cronbach's alpha of this questionnaire shows the acceptable value of 0.84 . The correlation matrix determinant equaled $3.56 \mathrm{E}-006$ and the stated variance equaled $0.61 \%$. This analysis has identified 8 factors that shown in table 5.

\section{Table 5}

Details of factor analysis of individual traits

\begin{tabular}{|c|c|c|c|c|c|c|c|}
\hline Factor & Name & Question & Factor Weight & Eigenvalues & \%of Variance & \%Cumulative & Alpha \\
\hline \multirow{6}{*}{1} & \multirow{6}{*}{ Openness } & 41 & 0.86 & \multirow{6}{*}{5.1} & \multirow{6}{*}{16.002} & \multirow{6}{*}{16.002} & \multirow{6}{*}{0.75} \\
\hline & & 30 & 0.79 & & & & \\
\hline & & 44 & 0.65 & & & & \\
\hline & & 25 & 0.54 & & & & \\
\hline & & 40 & 0.38 & & & & \\
\hline & & 5 & 0.37 & & & & \\
\hline \multirow{6}{*}{2} & \multirow{6}{*}{ Extraversion } & 21 & 0.68 & \multirow{6}{*}{3.22} & \multirow{6}{*}{10.07} & \multirow{6}{*}{26.07} & \multirow{6}{*}{0.70} \\
\hline & & 1 & 0.66 & & & & \\
\hline & & 26 & 0.64 & & & & \\
\hline & & 11 & 0.57 & & & & \\
\hline & & 31 & 0.49 & & & & \\
\hline & & 36 & 0.39 & & & & \\
\hline \multirow{3}{*}{3} & \multirow{3}{*}{ Conscientiousness } & 33 & 0.76 & \multirow{3}{*}{2.88} & \multirow{3}{*}{9,03} & \multirow{3}{*}{35.10} & \multirow{3}{*}{0.67} \\
\hline & & 3 & 0.75 & & & & \\
\hline & & 8 & 0.66 & & & & \\
\hline \multirow{5}{*}{4} & \multirow{5}{*}{ Emotional Stability } & 9 & 0.78 & \multirow{5}{*}{2.34} & \multirow{5}{*}{7.32} & \multirow{5}{*}{42.42} & \multirow{5}{*}{0.71} \\
\hline & & 24 & 0.75 & & & & \\
\hline & & 39 & 0.73 & & & & \\
\hline & & 34 & 0.63 & & & & \\
\hline & & 14 & 0.34 & & & & \\
\hline \multirow{3}{*}{5} & \multirow{3}{*}{ Agreeableness } & 12 & 0.71 & \multirow{3}{*}{1.75} & \multirow{3}{*}{5.47} & \multirow{3}{*}{47.9} & \\
\hline & & 17 & 0.54 & & & & 0.47 \\
\hline & & 2 & 0.42 & & & & \\
\hline & & 27 & 0.71 & & & & \\
\hline 6 & Warmth & 32 & 0.47 & 1.50 & 4.71 & 52.60 & 0.48 \\
\hline & & 42 & 0.38 & & & & \\
\hline & & 23 & 0.67 & & & & \\
\hline 7 & Self-Discipline & 43 & 0.63 & 1.35 & 4.3 & 56.83 & 0.51 \\
\hline & & 18 & 0.52 & & & & \\
\hline & & 6 & 0.71 & & & & \\
\hline 8 & Sociability & 7 & 0.53 & 1.33 & 4.16 & 61 & 0.38 \\
\hline & & 29 & 0.47 & & & & \\
\hline
\end{tabular}




\subsection{Psychological Well-Being}

The Cronbach alpha of this questionnaire is the acceptable value of 0.76 . The determinant of the correlation matrix equaled 0.083 and the stated variance equaled $61 \%$. The data gained from this analysis is provided in table 6.

\section{Table 6}

Details of factor analysis of PWB

\begin{tabular}{|c|c|c|c|c|c|c|c|}
\hline Factor & Name & Question & Factor Weight & Eigenvalues & $\%$ of Variance & $\%$ Cumulative & Alpha \\
\hline \multirow{3}{*}{1} & \multirow{3}{*}{ Purpose in life } & 4 & 0.827 & \multirow{3}{*}{3.137} & \multirow{3}{*}{26.14} & \multirow{3}{*}{26.14} & \multirow{3}{*}{0.7} \\
\hline & & 5 & 0.804 & & & & \\
\hline & & 3 & 0.662 & & & & \\
\hline \multirow{3}{*}{2} & \multirow{3}{*}{ Environmental mastery } & 8 & 0.801 & \multirow{3}{*}{1.809} & \multirow{3}{*}{15.075} & \multirow{3}{*}{41.215} & \multirow{3}{*}{0.58} \\
\hline & & 9 & 0.712 & & & & \\
\hline & & 12 & 0.626 & & & & \\
\hline \multirow{3}{*}{3} & \multirow{3}{*}{ Self satisfaction } & 1 & 0.777 & \multirow{3}{*}{1.219} & \multirow{3}{*}{10.159} & \multirow{3}{*}{51.374} & \multirow{3}{*}{0.54} \\
\hline & & 2 & 0.725 & & & & \\
\hline & & 14 & 0.39 & & & & \\
\hline \multirow{4}{*}{4} & \multirow{4}{*}{$\begin{array}{l}\text { Others and their } \\
\text { importance }\end{array}$} & 13 & 0.732 & \multirow{4}{*}{1.145} & \multirow{4}{*}{9,613} & \multirow{4}{*}{60.987} & \multirow{4}{*}{0.624} \\
\hline & & 6 & 0.683 & & & & \\
\hline & & 18 & 0.561 & & & & \\
\hline & & 17 & 0.428 & & & & \\
\hline
\end{tabular}

\section{Conclusion}

The factor analysis of Spector's job satisfaction questionnaire, provided 8 factors. These factors included promotion, salary and bonus (income), job itself, coworkers, processes, prohibiting and communications. In the factor analysis of job turnover, we arrived at a new array and categorization and the two factors included proper alternatives and evaluating the quitting. The factor analysis of individual personalities resulted in the categorization of eight factors. The factors included Openness, Emotional stability, Conscientiousness, Sociability, Agreeableness, Warmth, Extraversion and SelfDiscipline. In fact factors of agreeableness and conscientiousness have each been divided into two factors in our research. Among the well-being factors, four factors have been identified and categorized; purpose in life, environmental mastery, self-satisfaction, and others and their importance.

\section{References}

Akbaritabar, A. A., Mokarami, H., Nazifi, M., Rahi, A., \& Hosseinpouri, M. (2013). Psychometric properties of Spector's job satisfaction survey in the Iranian population. Koomesh, 14(3), 335-341.

Arnold, H. J., \& Feldman, D. C. (1986). Organizational Behavior. New York: McGraw-Hill.

Block, J. (2001). Millennial contrarianism: The five-factor approach to personality description 5 years later. Journal of Research in Personality, 35(1), 98-107.

Cascio, W. F. (1986). Managing hman resources:Productivity,quality of work life,profits. New York: McGraw-Hill.

George, D., \& Mallery, P. (2003). SPSS for windows step by step:A simple guide and reference,11.0 update(4th ed.). Boston: Allyn \& Bacon.

Gholami Fesharaki, M., Talebiyan, D., Aghamiri, Z., \& Mohammadian, M. (2012). Reliability and validity of "Job Satisfaction Survey" questionnaire in military health care workers. MilMed Journal, 13(4), 241-246.

Hom, P. W., \& Griffeth, R. W. (1995). Employee turnover. OH:South/Western.

John, O. P., \& Srivastava, S. (1999). The Big-Five trait Taxonomy:History,measurement, and theoretical lerspective. New York: Guilford.

Khanka, S. S. (2006). Organisational Behaviour. S. Chand. 
Lacity, M. C., Iyer, V. V., \& Rudramuniyaiah, P. S. (2008). Turnover intentions of Indian IS professionals. Information Systems Frontiers, 10(2), 225-241.

March, J. G., \& Simon, A. H. (1958). Organizations. New York: John wiley.

McGregor, I., \& Little, B. R. (1998). Personal projects, happiness, and meaning: on doing well and being yourself. Journal of personality and social psychology,74(2), 494.

Astrauskaite, M., Vaitkevičius, R., \& Perminas, A. (2011). Job Satisfaction Survey: A Confirmatory Factor Analysis Based on Secondary School Teachers' Sample. International Journal of Business \& Management, 6(5), 41-50.

Muchinsky, P. M., \& Morrow, P. C. (1980). A multidisciplinary model of voluntary employee turnover. Journal of Vocational Behavior, 17(3), 263-290.

Ryff, C. D. (1989). Happiness is everything, or is it? Explorations on the meaning of psychological well-being. Journal of personality and social psychology, 57(6), 1069.

Ryff, C. D. (2013). Psychological Well-Being Revisited: Advances in the Science and Practice of Eudaimonia. Psychotherapy and psychosomatics,83(1), 10-28.

Ryff, C. D., \& Keyes, C. L. M. (1995). The structure of psychological well-being revisited. Journal of personality and social psychology, 69(4), 719-727.

Smith, P. C., Kendall, L. M., \& Hulin, C. L. (1969). The Measurement of Satisfaction in Work and Retirement. Chicago: Rand McNally.

Wright, T. A., \& Bonett, D. G. (2007). Job satisfaction and psychological well-being as nonadditive predictors of workplace turnover. Journal of Management,33(2), 141-160. 